\title{
A population-based study of the costs of care for community-acquired pneumonia
}

\author{
M. Bartolomé*, J. Almirall*, J. Morera\#, G. Pera ${ }^{\Uparrow}$, V. Ortún ${ }^{+}$, J. Bassa*, I. Bolíbar ${ }^{\S}$, X. Balanzó*, \\ A. Verdaguer*, and the Maresme Community-Acquired Pneumonia Study Group (GEMPAC)
}

A population-based study of the costs of care for community-acquired pneumonia. M. Bartolomé, J. Almirall, J. Morera, G. Pera, V. Ortún, J. Bassa, I. Bolíbar, $X$. Balanzó, A. Verdaguer, and the Maresme Community-Acquired Pneumonia Study Group (GEMPAC). C) ERS Journals Ltd 2004.

ABSTRACT: In a population-based study, the consumption of resources for treating adult patients with community-acquired pneumonia was determined.

During a 2-yr period, all cases with a clinical and radiological suspicion of community-acquired pneumonia that occurred in patients aged $>14$ yrs in a community of 74,610 inhabitants were investigated prospectively.

Of 292 cases with a suspicion of community-acquired pneumonia, 224 were included (18.5\% misdiagnoses). The mean number of visits per patient was $4.5(72 \%$ in the primary care setting). Inpatient care was recommended in $59.8 \%$ of cases; after discharge, $44 \%$ of patients were managed in outpatient clinics. The mean direct cost of pneumonia treated in the hospital setting was $€$ (euros)1,553, whereas the mean cost of cases treated as outpatients was $€ 196$. A total of $15.7 \%$ of admissions were considered inappropriate and the length of stay could have been reduced by 3.5 days in the most severe cases. A reduction in inappropriate admissions and lengths of hospital stay would result in a decrease in cost of $17.4 \%$.

Community-acquired pneumonia in Maresme, Spain, occurs at a low incidence, although with a high percentage of hospitalisations (in part inappropriate), resulting in considerable costs.

Eur Respir J 2004; 23: 610-616.
*Consorci Sanitari de Mataró, Mataró, "Dept of Pneumology, Hospital Universitari Germans Trias i Pujol, Badalona, and "Dept of Epidemiology, Catalonian Institute of Oncology, Hospital Duran i Reinals, L'Hospitalet de Llobregat, ${ }^{+}$Faculty of Economics, Pompeu Fabra University, and ${ }^{\S}$ Servei d'Epidemiologia Clinica i Salut Pública, Hospital Santa Creu i Sant Pau, Universitat Autònoma de Barcelona, Barcelona, Spain.

Correspondence: J. Almirall, Intensive Care Unit, Hospital de Mataró, Carretera de Cirera s/n, E-08304 Mataró, Barcelona, Spain.

Fax: 34937417770

E-mail: jalmirall@csm.scs.es

Keywords: Community-acquired pneumonia, cost reduction, direct costs, length of stay, site of care

Received: July 42003

Accepted after revision: November 252003

This study was supported by a grant $(97 / 0718)$ from the Health Investigation Fund, Madrid, Spain.
Community-acquired pneumonia is an acute disease that may occur at any age. The overall rate ranges 2.6-13.4 cases per 1,000 persons annually $[1,2]$, with a high mortality rate. Indeed, pneumonia is the fifth to ninth leading cause of death in developed countries [3-6]. However, few population-based studies of community-acquired pneumonia treated in the primary care setting have been undertaken $[1,2,7,8]$. In a meta-analysis of the prognosis and outcomes of communityacquired pneumonia [9], only six of the 127 studies included in the review were carried out in ambulatory cohorts with radiographic confirmation, and one of the conclusions was that future investigations should focus greater attention on studying ambulatory patients.

The small number of cost-of-illness studies that have been undertaken in the primary care setting have usually been limited to the assessment of consumption of resources. In Spain, the cost of inpatient care for community-acquired pneumonia ranged $€$ (euros) $1,210-1,847[10,11]$, whereas the cost of treating pneumonia in hospital outpatient clinics was $€ 150$ [11]. Only one study was identified in which the costs of care in the primary care setting in relation to a paediatric population were calculated, and the total cost per episode was $€ 72$ [12]. All studies, however, have consistently shown that the costs of treating community-acquired pneumonia in patients requiring hospitalisation are four to eight times higher than the cost of outpatient care $[11,13]$. It seems that length of hospital stay is the variable primarily affecting costs of care [14-17]. In this respect, various studies have been conducted with the aim of establishing different strategies for reducing the percentage of hospitalisations and the length of stay [18-21].

For the purposes of the present study, the economic costs may be estimated from a social perspective as well as from the perspectives of the healthcare provider, the medical centre or the patients themselves. The objectives of this populationbased study were: 1) determination of the consumption of resources for treating community-acquired pneumonia; 2) comparison of the costs of care according to therapeutic decision, i.e. hospital admission versus outpatient care; and 3) development of a proposal yielding substantial cost savings. Costs were quantified from the perspective of the Catalonian healthcare service [22], which is the healthcare provider in Catalonia, given that healthcare management in Spain has already been transferred to the local governments of the various autonomous communities.

\section{Materials and methods}

Between December 1993 and November 1995, a study was conducted in a mixed residential/urban industrial population 
of the Maresme region of the Mediterranean coast in the province of Barcelona, Spain. All subjects aged $>14$ yrs, living in the area (annual population 74,610 inhabitants) and exhibiting lower respiratory tract infection with previously unrecorded focal signs on physical examination of the chest, and a definite diagnosis of community-acquired pneumonia confirmed by radiological findings, were assessed. Communityacquired pneumonia was defined as an acute lower respiratory tract infection, for which antibiotics were prescribed, associated with new focal signs on examination of the chest and a radiographic infiltrate indicative of pneumonia, which was required for all suspected cases. Definition of clinical suspicion included fever and respiratory symptoms (cough with/without expectoration and/or chest pain).

All physicians working in the 14 public primary care centres, private clinics and emergency departments of the reference hospitals participated in the reporting of cases. Patients with aspiration pneumonia or active pulmonary tuberculosis, or who were immunosuppressed (active cancer or acquired immune deficiency syndrome (AIDS)), had been discharged from hospital $<7$ days before the onset of symptoms or had come from nursing homes were excluded. Nursing homes in Spain are long-stay centres in which patients with chronic diseases requiring nursing care also live, such that pneumonia in these residents is considered nosocomial. Patients were followed until complete radiological resolution, and, in a second phase, those patients initially included in the study in whom the diagnosis was not confirmed because of a clinical progression and chest radiograph images not consistent with community-acquired pneumonia were excluded. The study was approved by the Ethics Committees of the participating hospitals.

Data were recorded prospectively and included the following: place of diagnosis; number of visits prior to diagnosis; antibiotic treatment prescribed; site of care; length of stay (for patients requiring inpatient care); duration of symptoms (fever, cough, chest pain, asthenia and dyspnoea); radiological resolution; number of visits after diagnosis or hospital discharge; and number of days required to return to normal daily activities (return to work in employed patients). Deaths related to any disease that occurred within 30 days after diagnosis were attributed to the community-acquired pneumonia.

The assessment of resources included primary care visits; general practitioner-initiated radiographs; general practitionerprescribed antibiotics; visits to the hospital emergency department; visits to hospital outpatient clinics; data on inpatient care, including length of stay; admission to the intensive care unit (ICU), antibiotics prescribed in hospital, transfer to another hospital, and readmission (any admission for the same cause within 1 month after diagnosis); number of days of inactivity; ambulance service use; and admission to a skilled nursing facility after hospital discharge. The use of health service resources and the corresponding costs were obtained from the 1997 official registered fees of the Catalonian healthcare service [22], and converted to euros for the year 2001 using the consumer price index. Direct costs included visits to the primary care centre, the hospital emergency department, outpatient clinics, length of hospital stay, length of stay in a skilled nursing facility, ambulance transport and outpatient antibiotic treatment.

Inappropriate hospital admissions and stays in hospital were assessed by retrospective review of the patient's chart. The risk classes defined by FINE et al. [23], based on a Pneumonia Severity Index (PSI) that stratifies patients into five risk classes, were used for assessing the appropriateness or inappropriateness of inpatient care. As shown in figure 1, specific additional variables, information on which was available at the time of the decision to hospitalise, that a)

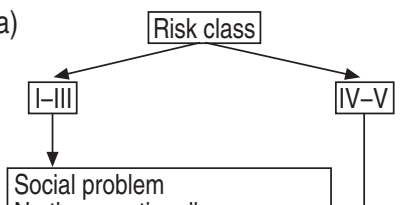

b)

No therapeutic adherence

Impaired oral intake

Need for oxygen therapy

Pleural effusion

Cavitation

Empyema

Multilobar pneumonia

Age $>70$ yrs

Nonresponse to previous therapy

Sepsis

Decompensated comborbidity

Severe CAP aetiology

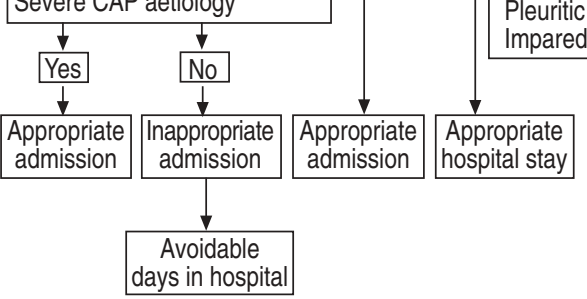

Fig. 1.-Algorithm for estimating cost reduction in inpatient care for community-acquired pneumonia (CAP) on the basis of: a) risk class; and b) criteria for short stay.

increase the likelihood of a poor prognosis in low-risk PSI classes were used. Inappropriate lengths of stay were determined by a modification of the algorithm proposed by MARRIE et al. [17] (fig. 1). All cases with missing values were excluded from this assessment.

\section{Statistical analysis}

Continuous data are expressed as mean \pm SD. The means of two continuous data were compared using an unpaired t-test or the Mann-Whitney U-test, and the means of three or more continuous data using analysis of variance or the KruskalWallis test. The relationship between two continuous data was assessed by means of Pearson's product-moment correlation coefficient. Categorical data are expressed as absolute numbers and percentages. The Chi-squared test or Fisher's exact test were used for comparison of categorical data. Patients who died during the study were excluded from the calculation of length of stay. Variables associated with the direct costs of treating community-acquired pneumonia in the univariate analysis $(\mathrm{p}<0.10)$ were included in a logistic regression model in which the effect of each variable on cost was adjusted by the remaining variables in the model. A p-value of $<0.05$ was considered significant.

\section{Results}

A flow chart detailing the composition of the study population is shown in figure 2 . Of the 292 patients initially included in the study, 17 had AIDS and were excluded. In 51 patients, $50 \%$ of whom had been hospitalised, the diagnosis of community-acquired pneumonia was not confirmed at follow-up (rate of misdiagnosis 18.5\%). Therefore, the study population consisted of 224 patients with communityacquired pneumonia, an annual incidence of 1.51 cases per 1,000 inhabitants. There were 126 males and 98 females with a mean \pm sD age of $55.1 \pm 20.5 \mathrm{yrs}$. Patients aged $>65 \mathrm{yrs}$ accounted for $37 \%$ of cases. A total of nine patients died, an 


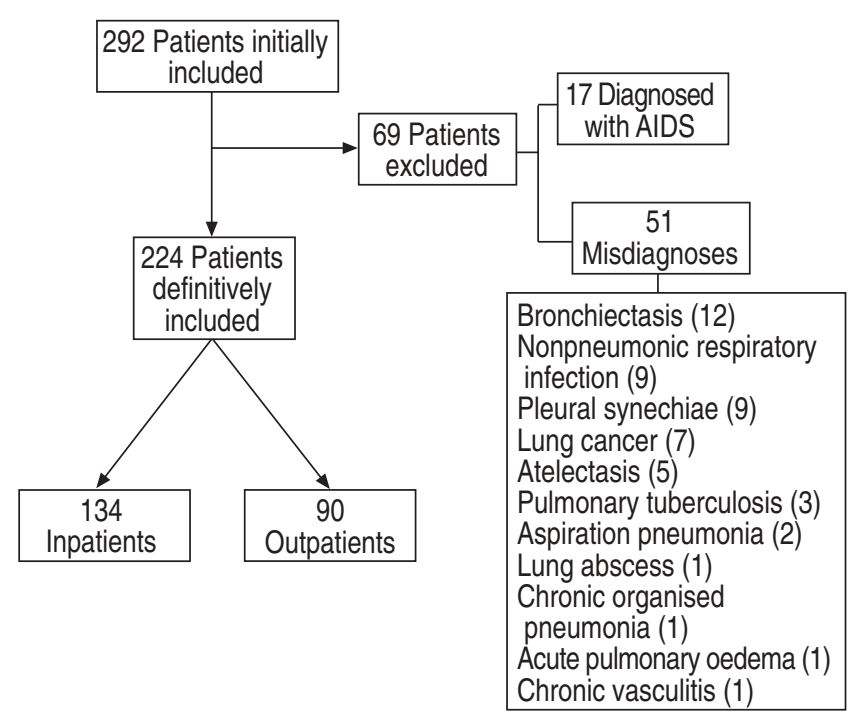

Fig. 2.-Flow diagram showing composition of study population. AIDS: acquired immune deficiency syndrome.

overall mortality rate of $4 \%$. Clinical characteristics, comorbidity and radiological findings according to site of care are shown in table 1.

\section{Consumption of resources}

The majority $(91.5 \%)$ of patients received treatment in public health institutions. The diagnosis of communityacquired pneumonia was made in a hospital emergency department in $79.4 \%$ of patients and in a primary care centre in $20.6 \%$. Only $40.2 \%$ of patients were diagnosed with community-acquired pneumonia at the initial medical consultation, $38.1 \%$ had made a previous visit for the same symptoms, $19.1 \%$ two visits and $2.6 \%$ three or more visits, with a mean \pm SD of $1.5 \pm 1.0$ visits. The number of visits before and after diagnosis of community-acquired pneumonia according to site of care is shown in table 2. The time flow diagram of site of diagnosis and visits before and after diagnosis of community-acquired pneumonia is shown in figure 3.

A total of $134(59.8 \%)$ patients were treated as inpatients and $90(40.2 \%)$ as outpatients. The mean \pm SD length of
Table 2.-Number of visits before and after diagnosis of community-acquired pneumonia in 224 patients according to site of care

\begin{tabular}{lccc}
\hline & Total & Inpatients & Outpatients \\
\hline $\begin{array}{l}\text { Subjects n } \\
\text { Before diagnosis } \\
\quad \text { Primary care centre }\end{array}$ & 224 & 134 & 90 \\
$\quad$ Patients n (\%) & $126(56)$ & $68(50)$ & $58(64)$ \\
$\quad$ Visits n (mean $\left.{ }^{\#}\right)$ & $195(1.55)$ & $112(1.65)$ & $83(1.43)$ \\
Hospital emergency dept & & & \\
$\quad$ Patients n (\%) & $16(7)$ & $6(4)$ & $10(11)$ \\
$\quad$ Visits n (mean $\left.{ }^{\#}\right)$ & $17(1.06)$ & $6(1)$ & $11(1.1)$ \\
After diagnosis & & & \\
Primary care centre & & & \\
$\quad$ Patients n (\%) & $210(94)$ & $123(91)$ & $87(97)$ \\
$\quad$ Visits n (mean $\left.{ }^{\#}\right)$ & $491(2.34)$ & $241(1.96)$ & $250(2.87)$ \\
Hospital emergency dept & & & \\
$\quad$ Patients n (\%) & $8(4)$ & $2(2)$ & $6(7)$ \\
$\quad$ Visits n (mean $\left.{ }^{\#}\right)$ & $12(1.5)$ & $3(1.5)$ & $9(1.5)$ \\
Hospital outpatient clinic & & & \\
$\quad$ Patients n $(\%)$ & $65(29)$ & $60(44)$ & $5(6)$ \\
$\quad$ Visits n (mean $\left.{ }^{\#}\right)$ & $70(1.1)$ & $63(1.05)$ & $70(1.08)$ \\
\hline
\end{tabular}

dept: department; ${ }^{*}$ : visits per patient.

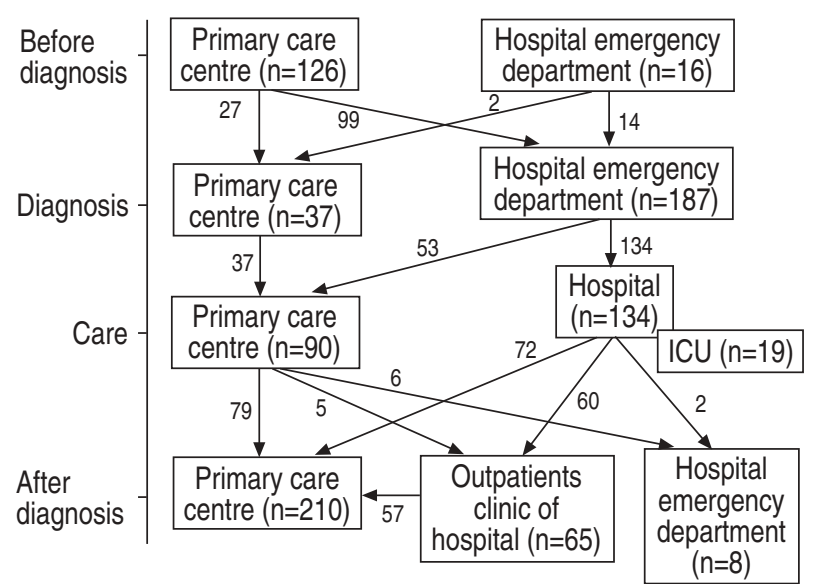

Fig. 3. - Time flow diagram showing site of visits before and after diagnosis of community-acquired pneumonia. ICU: intensive care unit.

Table 1.-Clinical characteristics, comorbidity and radiological findings in 224 patients with community-acquired pneumonia according to site of care

\begin{tabular}{|c|c|c|c|c|}
\hline & Total & Inpatients & Outpatients & $\mathrm{p}$-value \\
\hline Subjects $n$ & 224 & 134 & 90 & \\
\hline Males & $126(56.2)$ & $85(63.4)$ & $42(45.6)$ & 0.008 \\
\hline Age yrs & $55 \pm 20$ & $64 \pm 18$ & $42 \pm 17$ & $<0.001$ \\
\hline Age $>65$ yrs & $75(33.5)$ & $67(50.0)$ & $8(8.9)$ & $<0.001$ \\
\hline Public health institution care & $205(91.5)$ & $120(89.5)$ & $85(94.4)$ & 0.198 \\
\hline Comorbidity & $89(39.7)$ & $72(53.7)$ & $17(18.8)$ & $<0.001$ \\
\hline Chronic bronchitis & $65(29.0)$ & $54(40.3)$ & $11(12.2)$ & $<0.001$ \\
\hline Temperature ${ }^{\circ} \mathrm{C}$ & $38.0 \pm 1.0$ & $38.2 \pm 0.9$ & $37.7 \pm 0.9$ & $<0.001$ \\
\hline Respiratory frequency breaths $\cdot \min ^{-1}$ & $23 \pm 8$ & $26 \pm 8$ & $19 \pm 4$ & $<0.001$ \\
\hline \multicolumn{5}{|l|}{ Radiographic findings } \\
\hline Multilobar & $14(6.2)$ & $13(9.7)$ & $1(1.1)$ & 0.01 \\
\hline Bilateral pulmonary involvement & $11(4.9)$ & $10(7.5)$ & $1(1.1)$ & 0.053 \\
\hline Pleural effusion & $19(8.4)$ & $18(13.4)$ & $1(1.1)$ & $<0.001$ \\
\hline
\end{tabular}

Data are presented as mean \pm SD or n (\%). \#: Includes diabetes mellitus, congestive heart failure, asthma, chronic bronchitis, epilepsy, Parkinson's disease, neuromuscular disorders, swallowing dysfunction, dementia, chronic liver disease, chronic renal insufficiency and stable malignancy. 
hospital stay was $10.8 \pm 6.2$ days. Nineteen patients required ICU admission with a length of ICU stay of $3.3 \pm 2.4$ days and a length of hospitalisation of $17.5 \pm 9.5$ days. Patients who were not admitted to the ICU had a length of hospitalisation of $9.9 \pm 5.2$ days. After diagnosis, $44 \%$ of hospitalised patients made an appointment at the outpatient clinic of the hospital and were also visited by their general practitioners. Patients receiving outpatient care were mostly followed at the primary care centres, with $2.87 \pm 1.6$ visits per patient (table 2 ).

The mean \pm SD time to clinical resolution was $5.3 \pm 5.5$ days, return to work $22.9 \pm 13.3$ days, and return to usual activities $22.9 \pm 15.0$ days. Twenty days after diagnosis, only $55 \%$ of patients had returned to work.

The duration of treatment was $14.7 \pm 6.1$ days without significant differences in relation to site of care. Ambulatory patients were mostly treated with macrolides, whereas hospitalised patients were preferentially given cephalosporins (table 3). A total of $18.6 \%$ patients had been treated with antibiotics prior to diagnosis of community-acquired pneumonia. Intravenous antibiotic therapy lasted for $6.6 \pm 1.4$ days. Radiological resolution was achieved at 35 days in $89.3 \%$ of survivors.

\section{Costs of community-acquired pneumonia}

The mean \pm SD total annual cost of treating communityacquired pneumonia in the Maresme region was $€ 101,305 \pm 85$, $86.1 \%$ of which was incurred in association with inpatient care, $10.2 \%$ with primary care, $3.3 \%$ with care in skilled nursing facilities and $0.4 \%$ with ambulance services. Antibiotic therapy accounted for $22 \%$ of total costs (inpatient care $18.9 \%$, outpatient care $3.1 \%$ ) and visits before diagnosis $2.7 \%$. As shown in table 4, costs were significantly higher in patients aged $\geqslant 65$ yrs.

The cost of inpatient care was $€ 1,553 \pm 542$, of which $84.4 \%$ corresponded to hospitalisation, $10.2 \%$ to visits, $3.5 \%$ to stay in skilled nursing facilities, $1.5 \%$ to ambulatory treatment, and $0.4 \%$ to ambulance services. ICU treatment accounted for $15 \%$ of the costs of inpatient care. The cost of outpatient care

Table 3. - Antibiotic treatment in 224 patients with communityacquired pneumonia according to site of care

\begin{tabular}{lccc}
\hline & Total & Inpatients & Outpatients \\
\hline Subjects n & 224 & 134 & 90 \\
All penicillin derivs. & $16(7.1)$ & $12(9.0)$ & $4(4.4)$ \\
Quinolones & $6(2.7)$ & $4(3.0)$ & $2(2.2)$ \\
Macrolides & $147(65.5)$ & $71(53.0)$ & $76(84.4)$ \\
Cephalosporins & $114(50.9)$ & $105(78.4)$ & $9(10.0)$ \\
$\quad$ Second generation & $69(30.8)$ & $64(47.8)$ & $5(5.6)$ \\
$\quad$ Third generation & $71(31.7)$ & $67(50.0)$ & $4(4.4)$ \\
Aminoglycosides & $2(0.9)$ & $2(1.5)$ & 0 \\
Antiviral agents & $1(0.4)$ & $1(0.7)$ & 0 \\
Other & $3(1.3)$ & $2(1.5)$ & $1(1.1)$ \\
\hline
\end{tabular}

Data are presented as $\mathrm{n}(\%)$. deriv: derivative. was $€ 196 \pm 86$, of which $79 \%$ corresponded to primary care visits, $20.3 \%$ to antibiotic treatment and $0.7 \%$ to ambulance services. On multivariate analysis, the use of cephalosporins, which is not a first-choice agent, in patients treated as outpatients was the only significant factor associated with cost increases $(1.41$ times) $(\mathrm{p}<0.001)$. However, in the case of inpatient care, none of the antibiotics was associated with significant cost increases.

\section{Cost-savings}

The PSI could not be calculated in 11 patients with missing values. Therefore, the PSI was calculated in 123 of the 134 patients treated as inpatients. In 78 patients admitted to hospital, PSI risk classes were $<\mathrm{IV}$. In $30 \%$ of these patients, there were no reasons for inpatient care; thus it was considered that $15.7 \%$ of hospital admissions for communityacquired pneumonia were inappropriate. Treatment of these cases in the ambulatory setting would reduce the overall cost of treating community-acquired pneumonia by $14 \%$.

In patients admitted to hospital, fever subsided after a mean \pm SD of $4.2 \pm 11.7$ days and there were no reasons to justify prolongation of hospitalisation in $46.5 \%$ of cases. In the remaining $53.5 \%$, the reasons for continuing hospitalisation were respiratory failure in 26 cases, pleuritic pain in five, inability to maintain oral intake in three, tachypnoea in two and tachycardia in one. The length of stay for patients with inappropriate prolongation of hospitalisation was $8.9 \pm 4.1$ days compared to the proposed length of stay of $5.4 \pm 3.6$ days. A total of 242 avoidable days of hospitalisation were recorded. The reduction in hospital stay would represent a decrease in the cost of treating community-acquired pneumonia of $8.1 \%$, which would result in an annual reduction in costs of $17.4 \%$.

\section{Discussion}

Of the 224 episodes of community-acquired pneumonia, $8.5 \%$ were attended at private institutions, a datum that is difficult to compare with other studies since the use of private healthcare resources depends on the healthcare system of each study area. Despite the fact that primary care plays an important role in the management of community-acquired pneumonia, the low diagnostic yield ( $20 \%$ of cases) at this level is surprising. This may be explained by the lack of availability of chest radiography such that many patients are referred to the hospital emergency department, as well as for the tendency of patients in Maresme to seek care directly from the hospital emergency service [24]. A study carried out in Spain in the primary care setting showed that $29.7 \%$ of cases of community-acquired pneumonia were diagnosed at hospital emergency services [25]. In the study of WEINGARTEN et al. [26], 55\% of diagnoses of community-acquired pneumonia were established at the emergency department.

After discharge from hospital, $44 \%$ of patients visited both

Table 4.-Costs of treating community-acquired pneumonia according to age

\begin{tabular}{lccrr}
\hline & \multicolumn{3}{c}{ Cost $€$} & \\
\cline { 2 - 4 } & \multicolumn{1}{c}{ Total } & Age $<65$ yrs & Age $\geqslant 65$ yrs \\
\hline Inpatient & $1553 \pm 542(92.0)$ & $1506 \pm 348(86.6)$ & $1604 \pm 693(98.1)$ & 0.324 \\
Outpatient & $196 \pm 86(8.0)$ & $190 \pm 77(13.4)$ & $263 \pm 145(1.9)$ & 0.031 \\
All sites & $988 \pm 792$ & $769 \pm 700$ & $1458 \pm 779$ & $<0.001$ \\
\hline
\end{tabular}

Data are presented as mean \pm SD cost per case ( $\%$ total cost). $€$ : euro. 
the outpatient clinics of the hospital and primary care centres; thus $96.6 \%$ of patients attended at least one consultation with their practitioner. It should be noted that $10 \%$ of patients attended at the hospital emergency service and referred for ambulatory care were given appointments to visit the same service, although the management of these patients could had been performed at a less costly level, such as primary care. A total of 500 visits attributable to community-acquired pneumonia, including the three levels of primary care, hospital emergency departments and hospital outpatient clinics were made annually.

The present percentage of patients receiving inpatient care of 59.8 is greater than the $18-50 \%$ reported in other population-based studies [27, 28]. This may be explained by several factors, including easy access to the hospital [29] and availability of beds, the age of the population, comorbidity and subjective criteria in the decision to hospitalise in the local setting of Maresme. However, it has been shown that attending physicians always tend towards admission rather than outpatient care if there is any doubt about outcome [2], and that the physician's speciality also influences determination of the initial site of care [13]. The mean length of hospitalisation of 3.3 days is consistent with data reported in other studies [18, 30].

A total of $18.6 \%$ of the patients admitted to hospital had had antibiotic treatment initiated before diagnosis, a percentage much lower than the $40 \%$ reported by others [29, 31], and probably due to rapid consultation at the hospital emergency department at the onset of symptoms. Macrolides were the class of antibiotic most frequently prescribed. This is in accordance with the recommendations of the Spanish Society of Respiratory Diseases at the time of the study [32]. Conversely, GILBERT et al. [30] identified macrolides as the most favourable cost-effective agents in $>2,000$ patients with community-acquired pneumonia in the Pneumonia patient Outcomes Research Team multicentric study. Cephalosporins were the second antimicrobials prescribed ahead of penicillins, which is a relevant fact given that cephalosporins are not first-line antibiotics in the ambulatory treatment of communityacquired pneumonia and are associated with a significant cost increase. The mean duration of outpatient antibiotic treatment was 14 days, somewhat longer than the 8-10 days proposed for low-risk classes of community-acquired pneumonia [32]. Intravenous antibiotic treatment lasted for 6.6 days, which is similar to data reported in other studies [18, 28, 30]. However, 2-3 days of intravenous antibiotic therapy may be equally effective and would be associated with a decrease in the length of stay and reduction of cost in low-risk classes $[18,21]$. In the present study, it is possible that the high percentage of patients receiving inpatient care and prolonged hospitalisation were related to the absence of readmissions $(4.1-14.1 \%$ in the literature) $[11,26,30]$ or admission of patients initially treated as outpatients $(2.8-7.1 \%$ in the literature) $[30,31]$. The time interval from clinical resolution to a return to normal daily activities of 22 days is longer than the 6-8 days reported for patients with low-risk classes in some studies $[26,28]$ but shorter than the intervals of $>40$ days reported by others [13]. Delay in returning to normal activities may be related to the persistence of some symptoms, such as asthenia, especially in Chlamydia pneumonia [33], or to the time awaiting radiological resolution. Although, in older patients, there was a greater delay in returning to normal activities, differences compared to patients aged $<65$ yrs were not significant.

In the present study, the only source used for estimating the direct costs of both outpatient and inpatient care was the official registered fees of the Catalonian healthcare service, the governmental body providing free public healthcare services for all citizens in Catalonia. Although the method applied is perfectly adequate for the entire autonomous community of Catalonia and the present results would probably be generalisable to other autonomous communities in Spain, the marked differences in the healthcare systems of different countries are an important limitation to the external validity of this study. However, valid inferences may probably be established for the percentages of costs related to the different levels of care, particularly in many European countries, in which primary care is a first-line healthcare system, completely different from that in the USA and Canada.

Of the 205 patients treated in the public healthcare system, $59.8 \%$ were treated as inpatients and accounted for $92 \%$ of the annual costs of community-acquired pneumonia. A large study carried out by GUEST and MORRIS et al. [4] in 1992/1993 using data from the National Health Service in the UK found that the $32 \%$ of all episodes of community-acquired pneumonia treated in hospital accounted for $96 \%$ of the annual cost. NiEDERMAN et al. [5] and WitTle et al. [13] in the USA have reported that 95 and $81 \%$, respectively, of the overall costs of treating pneumonia were associated with inpatient care. In the study of BIRNBAUM et al. [34], carried out in employed persons, this percentage decreased to 63 .

The cost of treating a patient with community-acquired pneumonia in hospital was $€ 1,553,7.9$ times higher than for outpatient care (€196). If the comparison was made with community-acquired pneumonias exclusively treated in the primary care setting, this proportion increased to 12.2. In other nonpopulation-based studies, the direct costs of inpatient care were 4.4 and 8.0 times higher than those of outpatient care $[11,13]$. In other studies carried out in Spain, the direct costs of inpatient care were $€ 1,210$ [11] and 1,847 [10], respectively, with $€ 149$ for patients attended in hospital outpatient clinics [11] and $€ 72$ in ambulatory paediatric patients [12]. When patients were stratified by age, the cost of treating patients aged $>65$ yrs was significantly higher than that in patients aged $<65 \mathrm{yrs}$, but older age was not an independent predictor of costs in the logistic regression analysis, probably due to the effect of other variables, such as severity of illness and comorbidity. Conversely, the percentage of cases of community-acquired pneumonia not diagnosed at the initial visit suggests that primary care physicians are reluctant to order chest radiographs in febrile episodes. The need to perform radiographic studies in the primary care setting is controversial. In Europe, there is a trend towards treating pneumonia without radiological confirmation because it is considered that, given the low cost of ambulatory treatment, a 25\% diagnostic error would represent a $1 \%$ variation in cost [4]. However, if more radiographic studies were performed in the primary care setting, the diagnostic yield would increase, which, in turn, would contribute to reducing the number of consultations at hospital emergency services and the possibility of inappropriate admissions to hospital. Moreover, radiological confirmation of the pneumonic infiltrate is important given that it has been shown that previous respiratory infection is a risk factor for community-acquired pneumonia [35]. Conversely, if the 51 patients tentatively diagnosed as having communityacquired pneumonia in whom the diagnosis was not confirmed had been included in the present study, the annual cost would have been increased by $18 \%$. For this reason, it is important to extend the radiographic follow-up of patients until resolution in order to prevent the inclusion of false negative cases.

The variability in direct costs is explained principally by the length of stay [36], and there is general agreement that a substantial number of patients with communityacquired pneumonia that could be treated as outpatients are hospitalised [11]. Data from the present study indicate that 
$14 \%$ of hospital admissions could be avoided, with a reduction in the total costs of community-acquired pneumonia attributable to hospitalised patients from 92.0 to $88.6 \%$. In other studies using different methods and from the hospital perspective, a 26 or $36 \%$ rate of inappropriate hospital admissions has been reported $[11,17]$. The present results should be interpreted taking into account the fact that the data required for calculation of the PSI score were collected retrospectively and that such data were not obtained for ambulatory patients. Moreover, a number of patients were excluded from the calculation of the PSI score due to missing values. However, the present findings are consistent with the results of others reporting a mean reduction in the length of hospital stay of 2 days [29]. It should be noted that $22 \%$ of patients could have been discharged from hospital during the first 3 days after admission, and so short hospitalisations followed by care at other levels (primary care, home-care services, hospital outpatient clinics or skilled nursing facilities) should be strongly considered. Although cost-savings due to inappropriate hospital stays were $8.1 \%$, this percentage should be lower because it was calculated according to the mean cost of hospital stay despite it being known that $32 \%$ of costs are consumed during the first 2 days of hospitalisation and that costs decrease thereafter [16]. Overall, 242 avoidable days in hospital were estimated, a figure lower than what might be expected taking into account the high percentage of inpatient care in the present study, and compared with the results of GonZALEZ-MORALEJA et al. [11], who reported 352 inappropriate days of hospitalisation in 131 patients. In addition, reduction in the consumption of resources should be assessed from the point of view of marginal costs. Thus the fact of being hospitalised for a shorter period may be associated with an increase in the number of readmissions as well as an increase in the number of patients initially treated in the primary care setting that require further admission to hospital, such that the percentage of cost reduction of 17.4 may vary substantially.

It is concluded that community-acquired pneumonia exerts an important economic burden with consumption of resources related to a high percentage of inpatient care, long duration of antibiotic therapy and a considerable number of visits at different healthcare levels.

Acknowledgements. The authors are grateful to C. Mas for secretarial assistance and M. Pulido for editing the manuscript and editorial assistance.

Members of the Maresme Community-Acquired Pneumonia Study Group (GEMPAC): Primary care centres: J.M. de Salas, J. Costa, M. Tristany, M. J. Grau, S. Sancho, E. Miguel, M. Fradera, I. Ochoa and A. Quilez, Basic Health Area of Arenys (Catalan Health Institute (ICS)); V. Marina, P. Subias, B. Jimeno, A. Bradnovich, M. Rodriguez, E. Ramon, A. Gardella and C. Ginés, Basic Health Area of Canet de Mar and Sant Pol de Mar (ICS); J.C. Montero, P. Flores, P. Serra, E. Torrellas, I. Buxadé, J. Mussoll and M. Gomez, Basic Health Area of Cirera Molins (Consorci Sanitari del Maresme); X. Mestres, A. Armada, J. Mallafré, M. Roger, M.T. Gros and N. Les, Basic Health Area of Ronda Cerdanya (ICS); J. Joanola, J. Doménech, M. Bundó, $\mathbf{M}^{\mathrm{a}}$. Trilla, J. Massons, J. Montero and E. Zurilla, Basic Health Area of Ronda Prim (ICS); M. Alegre, M. Papiol, O. Martí, M. Catalá, M.A. Martinez and E. Diaz, Basic Health Area of Argentona (Consorci Sanitari del Maresme); P. Torán, M.M. Aizpurua, G. Lozano, J. Casals, J. Sorribes and D. Torrellas, Basic Health Area of Gatassa (ICS); A. Casas, J. Bernad, A. de Montoliu, J. Gaya, R. Vallés,
A. Vazquez, R. Peiró, G. Aresté, N. Mengual and M.C. Viñes, Basic Health Area of Vilassar de Mar (ICS); E. Almerich, M.A. Lopez, J. Bel, A. Gosalves, S. Macip, E. Carrillo, P. Paulo, M. Pol, J. Sala and P. Mir, Basic Health Area of Pineda (ICS); J.L.L. Anglada, J. Salabarnada, E. Sanz, F. Gorgas, A. Ribas, E. Fau, I. Pellicer and S. Morales, Basic Health Area of Riera, Mataró (ICS); E. Burdoy, L.L. Busquets, S. de Castro, M. Bartolomé, E. Corona and Y. Verde, Basic Health Area of Riera, Mataró (Consorci Sanitari del Maresme); A. Borrás and F. Aznar (Centre Mèdic de Mataró, Mataró); F. Riera, A. Vazquez and P. Gil (GEMA S. L., Mataró); and M. Serra-Prat (Research Unit, Consorci Sanitari del Maresme). Acute care hospitals: O. Parra, Hospital del Sagrat Cor, Barcelona; F. Riera, Hospital de Barcelona, Barcelona; P. Tudela, Hospital Universitari Germans Trias i Pujol, Badalona; R. Tarradas and M. Berrocal, Hospital Sant Jaume, Calella; J. Bassa, M. Daza, F. Casarramona, J.A. Capdevila and J.C. Yébenes, Hospital de Mataró, Barcelona, Spain.

\section{References}

1. Almirall J, Bolíbar I, Vidal $\mathrm{J}$, et al. Epidemiology of community-acquired pneumonia in adults: a populationbased study. Eur Respir J 2000; 15: 757-763.

2. Jokinen $\mathrm{C}$, Heiskanen $\mathrm{L}$, Juvonen $\mathrm{H}$, et al. Incidence of community-acquired pneumonia in the population of four municipalities in eastern Finland. Am J Epidemiol 1993; 137: 977-988.

3. Lave JR, Fine MJ, Sankey SS, Hanusa BH, Weissfeld LA, Kapoor WN. Hospitalized pneumonia. Outcomes, treatment patterns, and costs in urban and rural areas. J Gen Intern Med 1996; 11: 415-421.

4. Guest JF, Morris A. Community-acquired pneumonia: the annual cost to the National Health Service in the UK. Eur Respir J 1997; 10: 1530-1534.

5. Niederman MS, McCombs JS, Unger AN, Kumar A, Popovian R. The cost of treating community-acquired pneumonia. Clin Ther 1998; 20: 820-837.

6. Muñoz Alcañiz A, Sobrino Vegas L, Velasco Muñoz ML, Cano Portero R, Mateo Ontañón S. Vigilancia de las neumonías en España. Bol Epid Sem 1997; 5: 29-36.

7. Oseasohn R, Skipper BE, Tempest B. Pneumonia in a Najavo community. Am Rev Respir Dis 1978; 11: 1003-1009.

8. Woodhead MA, Macfarlane JT, McCracken JS, Rose DH, Finch RG. Prospective study of the aetiology and outcome of pneumonia in the community. Lancet 1987; 2: 671-674.

9. Fine MJ, Smith MA, Carson CA, et al. Prognosis and outcomes of patients with community-acquired pneumonia. A meta-analysis. JAMA 1996; 274: 134-141.

10. Fernández Álvarez R, Gullón Blanco JA, Rubinos Cuadrado $\mathrm{G}$, et al. Neumonía adquirida en la comunidad: influencia de la duración de la antibioterapia intravenosa en la estancia hospitalaria y relación coste/efectividad. Arch Bronconeumol 2001; 37: 366-370.

11. González-Moraleja J, Sesma P, González C, Lopez ME, Garcia JF, Alvarez-Sala JL. ¿Cuál es el coste de las neumonías que ingresamos inadecuadamente? Arch Bronconeumol 1999; 35: 312-316.

12. Buñuel Álvarez JC, Vila Pablos C, Tresserras González E, et al. Estudio de costes del proceso diagnóstico-terapéutico de la neumonía infantil adquirida en la comunidad en Atención Primaria. Rev Pediatr Aten Primaria 1999; 1: 4353.

13. Whittle J, Lin CJ, Lave JR, et al. Relationship of provider characteristics to outcomes, process, and costs of care for 
community-acquired pneumonia. Med Care 1998; 36: 977987.

14. McCormick D, Fine MJ, Coley CM, et al. Variation in length of hospital stay in patients with community-acquired pneumonia: are shorter stays associated with worse medical outcomes? Am J Med 1999; 107: 5-12.

15. Siegel RE. How long a stay in the hospital is needed for patients with community-acquired pneumonia? Am J Med 2000; 109: 434 436.

16. Fine MJ, Pratt HM, Obrosky DS, et al. Relation between length of hospital stay and costs of care for patients with community-acquired pneumonia. Am J Med 2000; 109: 378385.

17. Marrie TJ, Lau CY, Wheeler SL, Wong CJ, Vandervoort MK, Feagan BG. A controlled trial of a critical pathway for treatment of community-acquired pneumonia. CommunityAcquired Pneumonia Intervention Trial Assessing Levofloxacin. JAMA 2000; 283: 749-755.

18. Siegel RE, Halpern NA, Almenoff PL, Lee A, Cashin R, Greene JG. A prospective randomized study of inpatient $i v$. antibiotics for community-acquired pneumonia. The optimal duration of therapy. Chest 1996; 110: 965-971.

19. Fine MJ, Singer DE, Phelps AL, Hanusa BH, Kapoor WN. Differences in length of hospital stay in patients with community-acquired pneumonia: a prospective four-hospital study. Med Care 1993; 31: 371-380.

20. Gertman PM, Restuccia JD. The appropriateness evaluation protocol: a technique for assessing unnecessary days of hospital care. Med Care 1981; 19: 855-871.

21. Cunha BA. Community-acquired pneumonia. Cost-effective antimicrobial therapy. Postgrad Med 1996; 99: 109-123.

22. Departament de Sanitat i Seguretat Social. Decret del 23 de desembre de 1997. DOGC 1997; 2547: 15080-15087.

23. Fine MJ, Auble TE, Yealy DM, et al. A prediction rule to identify low-risk patients with community-acquired pneumonia. N Engl J Med 1997; 336: 243-250.

24. Bolíbar I, Balanzó X, Armada A, et al. El impacto de la reforma de la atención primaria en la utilización de servicios de urgencias hospitalarios. Med Clin (Barc) 1996; 107: 289295.

25. Santos de Unamuno C, Llorente San Martín MA, Carandell
Jäger E, et al. Lugar de atención, etiología y tratamiento de las neumonías adquiridas en la comunidad de Palma de Mallorca. Med Clin (Barc) 1998; 110: 290-294.

26. Weingarten SR, Riedinger MS, Hobson P, et al. Evaluation of a pneumonia practice guideline in an interventional trial. Am J Respir Crit Care Med 1996; 153: 1110-1115.

27. Macfarlane J. An overview of community acquired pneumonia with lessons learned from the British Thoracic Society study. Semin Respir Infect 1994; 9: 153-165.

28. Gleason PP, Kapoor WN, Stone RA, et al. Medical outcomes and antimicrobial costs with the use of the American Thoracic Society guidelines for outpatients with community-acquired pneumonia. JAMA 1997; 278: 32-39.

29. Porath A, Schlaeffer F, Lieberman D. Appropriateness of hospitalization of patients with community-acquired pneumonia. Ann Emerg Med 1996; 27: 176-183.

30. Gilbert K, Gleason PP, Singer DE, et al. Variations in antimicrobial use and cost in more than 2,000 patients with community-acquired pneumonia. Am J Med 1998; 104: 1727.

31. Zalacaín R, Talayero N, Achótegui V, Corral J, Barrena I, Sobradillo V. Neumonía adquirida en la comunidad. Fiabilidad de los criterios para decidir tratamiento ambulatorio. Arch Bronconeumol 1997; 33: 74-79.

32. Dorca J, Bello S, Blanquer J, et al. Diagnóstico y tratamiento de la neumonía adquirida en la comunidad. Arch Bronconeumol 1997; 33: 240-246.

33. Marrie TJ, Peeling RW, Fine MJ, Singer DE, Coley CM, Kapoor WN. Ambulatory patients with communityacquired pneumonia: the frequency of atypical agents and clinical course. Am J Med 1996; 101: 508-515.

34. Birnbaum HG, Morley M, Greenberg PE, Cifaldi M, Colice GL. Economic burden of pneumonia in an employed population. Arch Intern Med 2001; 161: 2725-2731.

35. Almirall J, Bolíbar I, Balanzó X, González CA. Risk factors for community-acquired pneumonia in adults: a populationbased case-control study. Eur Respir J 1999; 13: 349-355.

36. Cots Reguant F, Castells Oliveres X, García Altés A, Saez Zafra M. Relación de los costes directos de hospitalización con la duración de la estancia. Gac Sanit 1997; 11: 287295. 